\title{
EFFECT OF CARBURIZING AND HARDENING TEMPERATURE ON THE ENDURANCE OF FORMING DIES FROM STEEL R6M5
}

\author{
I. N. Stepankin, ${ }^{1}$ V. M. Ken'ko, ${ }^{1}$ and A. A. Boiko'
}

Translated from Metallovedenie i Termicheskaya Obrabotka Metallov, No. 3, pp. 19 - 23, March, 2013.

\begin{abstract}
Results of a study of the effect of carburizing of the forming surfaces of cold upset dies from high-speed si R6M5 and of the hardening temperature on the structure and properties of the dies are presented. It is she that the hardness and endurance of the carburized tools can be raised by hardening from lower temperatun
\end{abstract}

Key words: steel R6M5, carburizing, hardening, stress-strain state, endurance of tools.

\section{INTRODUCTION}

The endurance of tools produced from high-speed steels depends on the chemical composition of the steel and on the modes of heat and thermochemical treatment determining the structure of the steel, i.e., the grain size, the degree of alloying of martensite (the a-phase), the content of retained austenite, the content of carbides and their composition.

Growth in the quenching temperature of high-speed steels is accompanied by increase in the hardness, in the ultimate bending strength, the endurance limit and the heat resistance, because the degree of alloying of the a-phase with carbon and alloying elements increases due to dissolution of the $\mathrm{M}_{23} \mathrm{C}_{6}$ carbides and, partially of the $\mathrm{M}_{6} \mathrm{C}$ carbides. However, the strength and the toughness of the steels at higher temperatures decrease markedly due to the growth of grains. These characteristics can be raised by lowering the temperature of heating for quenching, while the hardness and the wear resistance can be increased by diffusion modification of the functional surfaces of the tools [1-5]. The hardness of steel R6M5 upon heat treatment is affected substantially by precipitation hardening, which depends on the degree of alloying of the austenite and of the martensite, on the type of the carbides formed during tempering and on the content of the carbides.

The aim of the present work was to study the possibility of elevation of the endurance of cold-upsetting dies from steel R6M5 by carburizing the forming surfaces and lowering the quenching temperature.

P. O. Sukhoy Gomel State Engineering University, Gomel, Belarus (e-maii: igor-siepankin(a mail.ru).

\section{METHODS OF STUDY}

The specimens for the study and the experimental ar cles chosen to test the developed process were produc from high-speed steel R6M5 in the state as delivered.

The specimens were subjected to a standard treatme i.e., triple tempering for $1 \mathrm{~h}$ at $560^{\circ} \mathrm{C}$ (batch /). We al studied carburized specimens quenched right after the carh rization and then subjected to triple tempering for $1 \mathrm{~h}$ $560^{\circ} \mathrm{C}$ (batches 2, 3and4).

Carburizing was performed at $950^{\circ} \mathrm{C}$ in an atmosphere natural gas (methane) for $8 \mathrm{~h}$ and followed by quenchir The second batch of specimens was quenched from the c; burization temperature in order to study the possibility to without an additional heating to a higher temperature. $\mathrm{T}$ third and forth batches were heated to 1050 and $1150^{\circ} \mathrm{C}$, spectively, right after the carburization in a salt bath with hold of $15 \mathrm{sec}$ to $1 \mathrm{~mm}$ of the thickness in the smallest se tion. The maximum quenching temperature equal to $1150^{\prime}$ was chosen according to the criterion of ultimate residi compressive stresses in the carburized layer, which provo its detachment.

Quenching was performed in an isothermal mode. In $\mathrm{t}$ first stage the articles were cooled to $600^{\circ} \mathrm{C}$ in a salt ba When the temperature over the cross section was leveled, cooling was continued to room temperature by an air stre from an industrial manifold (at a pressure of $5 \times 10^{5} \mathrm{~Pa}$ ).

Numerical studies of the stressed state of the formi dies were performed using the finite-element method imp mented by the ANSYS software. Breaking into finite e ments was performed in accordance with the complexity the forming surface with the use of a Solid92 10-site eleme 
The internal stresses appearing in the hardened layer as a result of heat treatment were computed by a method based on measuring the deflection arising due to layer-after-layer dissolution of one of the surfaces of a carburized plate specimen $120 \mathrm{~mm}$ long, $10 \mathrm{~mm}$ thick and $20 \mathrm{~mm}$ wide [3]. The thickness of the diffusion layer determined in terms of the distribution of microhardness $\mathrm{H}_{200}$ was $0.4-0.6 \mathrm{~mm}$.

Metallographic analysis of diffusion layers in all the stages of the study was performed with the help of a TESCAN electron microscope (Czechia) with a digital attachment at a voltage of $20 \mathrm{kV}$ and a DRON-7 x-ray diffractometer with a 2.0BSV27-Co tube at a voltage of $40 \mathrm{kV}$ and a current intensity of 30 ц. The volume fraction of carbide particles was determined from electron micrographs by the method of secants. The hardness of the processed surfaces was measured with the help of a Rockwell device, the microhardness was measured using a PMT-3 device at a load of $200 \mathrm{~g}$.

\section{RESULTS AND DISCUSSION}

It has been shown that carburization of steel R6M5 at $950^{\circ} \mathrm{C}$ conducted in an atmosphere of natural gas for $8 \mathrm{~h}$ saturates the surface layers with carbon to $1.6-1.8 \%$ [5]. This increases the content of the $\mathrm{M}_{6} \mathrm{C}$ carbides and of the easiersoluble $\mathrm{M}_{23} \mathrm{C}_{6}$ carbides [1]. These carbides are the main sources from which the austenite is saturated with carbon and alloying elements. Heating for quenching yields a more carbon-saturated austenite, which promotes formation of high-carbon martensite after the quenching and intensifies the precipitation hardening in tempering. The surface hardness of the carburized specimens of steel R6M5 after quenching and triple tempering at $560^{\circ} \mathrm{C}$ is $65-66 \mathrm{HRC}$ in-

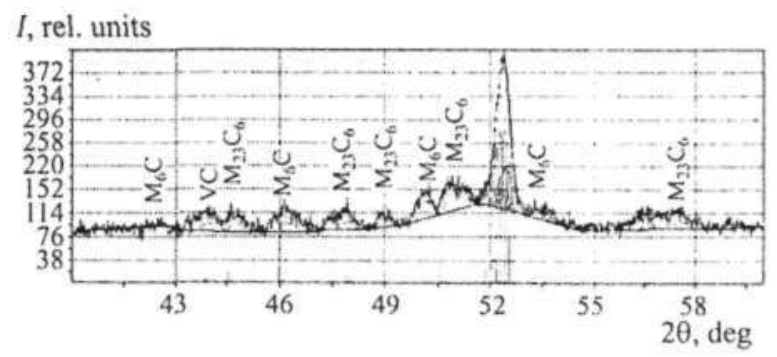

Fig. 1. A fragment of an x-ray diffractogram $\left(\mathrm{CoK}_{\alpha \alpha}\right)$ from surface layers of steel R6M5 after carburizing and quenching from $950^{\circ} \mathrm{C}$ ( $I$ is the radiation intensity).

dependently of the quenching temperature in the range of $950-1150^{\circ} \mathrm{C}$.

The hardness of the core depends on the temperature of quenching performed after carburization. After quenching from $950^{\circ} \mathrm{C}$ the hardness is 55 -- $57 \mathrm{HRC}$ due to the low saturation of the austenite and, correspondingly, of the martensite with carbon [1]. Only $1 \%$ of the $\mathrm{M}_{23} \mathrm{C}_{6}$ carbides contained in the steel dissolves at this temperature, while the austenite is saturated with carbon, chromium and partially with vanadium due to these very carbides The main mass of the carbides remains undissolved, which is proved by the -x-ray diffractograms (Fig. 1) and by the photographs of the microstructure (see Fig. 2b). The volume fraction of the carbide phase in Fig. $2 b$ amounts to $70 \%$.

Heating to $1050^{\circ} \mathrm{C}$ for quenching increases the rate of the dissolution of $\mathrm{M}_{23} \mathrm{C}_{6}$ carbides and the degree of their solubility (to 7\%). The content of carbon and alloying elements in the austenite increases too, which raises the hardness after quenching and triple tempering to 60-61 HRC. The volume of the carbide phase decreases to $50 \%$ (see Fig. 2c). After

Fig. 2. Microstructure of surface layer of steel R6M5 after quenching and triple tempering at $560^{\circ} \mathrm{C}$ : a) quenching from $1220^{\circ} \mathrm{C}$ witharburizing; $b, c, d$ ) prelimiary carburizing and quenching for 950,1050 and $1150^{\circ} \mathrm{C}$ reproctively.
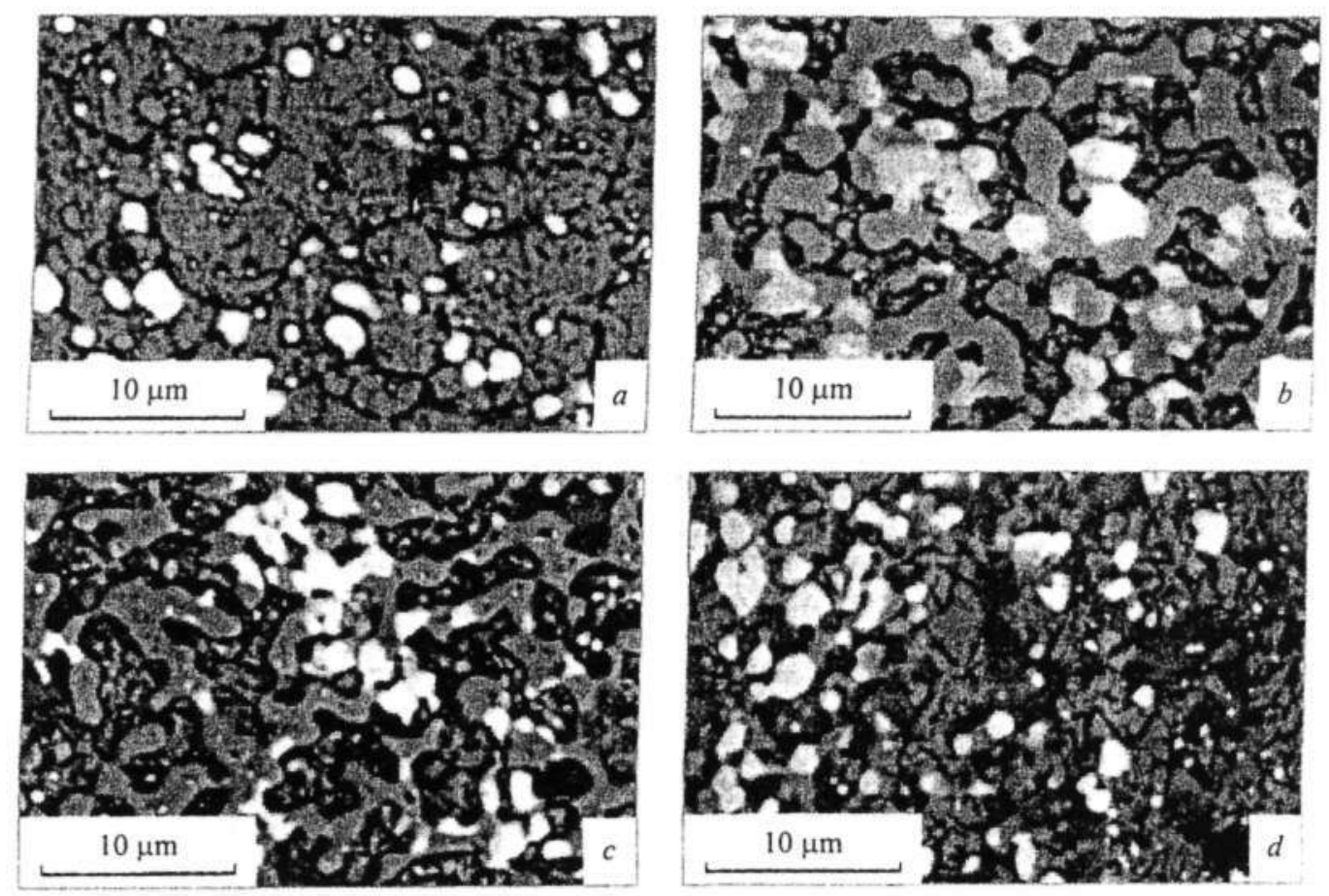

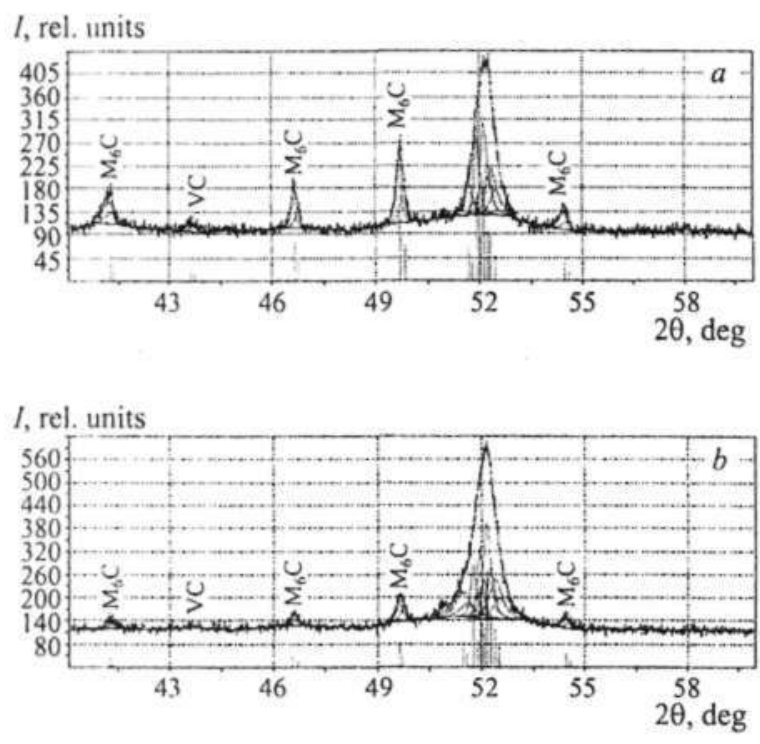

Fig. 3. A fragment of an x-ray diffractogram $\left(\mathrm{CoK}_{\alpha}\right)$ from surface layers of steel R6M5 quenched from $1150^{\circ} \mathrm{C}(a)$ and $1220^{\circ} \mathrm{C}(b)$ ( $I$ is the radiation intensity).

heating for quenching to $1150^{\circ} \mathrm{C}$ the $\mathrm{M}_{23} \mathrm{C}_{6}$ carbides dissolve virtually totally and the $\mathrm{M}_{6} \mathrm{C}$ carbides dissolve partially (about $6 \%$ of the content in the steel) as well as a low amount of the MC carbides (Fig. 3a). This provides a higher degree of saturation of the austenite and of the martensite with carbon and alloying elements ( $\mathrm{Cr}, \mathrm{W}, \mathrm{Mo}$ and $\mathrm{V})$. Growth in the degree of alloying of the a-phase with the quenching temperature is proved by the shift of the peak of its maximum intensity in the x-ray diffractograms toward lower angles 20 (from $52.3880^{\circ}$ to $52.1290^{\circ}$ ) and by the growth in the lattice constant $d$ from 0.20264 to $0.20357 \mathrm{~nm}[7,8]$. The hardness after quenching and triple tempering increases to 62 $63 H R C$, i.e., matches the value obtained due to a standard treatment from $1220^{\circ} \mathrm{C}$. The carbide composition is similar too, but the content of the $\mathrm{M}_{6} \mathrm{C}$ carbides retained in the structure after quenching from $1220^{\circ} \mathrm{C}$ is much lower (see Fig. 2d), which is confirmed by the decrease in the intensity of the peaks of the $\mathrm{M}_{6} \mathrm{C}$ carbides in the x-ray diffractograms (Fig. $3 b$ ). When the steel is heated above $1150^{\circ} \mathrm{C}$, the content of tungsten, molybdenum and carbon in the austenite increases due to the dissolution of the $\mathrm{M}_{6} \mathrm{C}$ carbides. However, at a temperature exceeding $1220^{\circ} \mathrm{C}$ the austenite grains grow to No. 10-9. The quenching yields coarse acicular marten-

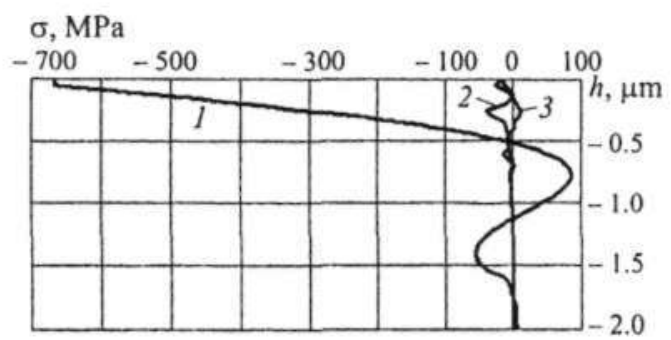

Fig. 4. Distribution of residual stresses in surface layer of ste R6M5 after carburizing and quenching from different temperature l) $1150^{\circ} \mathrm{C}$; 2) $1050^{\circ} \mathrm{C}$; 3$) 950^{\circ} \mathrm{C}$

site (with a size exceeding 4 scale divisions), which lowe the toughness and the strength of the steel.

The surface carburized layer of steel R6M5 contains : elevated content of carbon even at a temperature of $950^{\circ}$ ( which is sufficient for formation of high-carbon martensi after quenching at a high content of preserved carbides; th makes it possible to provide a surface hardness of 65 $66 \mathrm{HRC}$ after triple tempering at $560^{\circ} \mathrm{C}$. At the same tirr the hardness of the core is only 55 - $57 \mathrm{HRC}$ (see batch 4 Table 1). This gives rise to gradients of the compositic structure and properties over the depth (see Table 1).

Saturation of the surface of the steel with carbon low the temperature of the start of martensitic transformation? this layer. Therefore, the martensitic transformations quenching begin in deep layers and then develop in the $\mathrm{s}$ face layer, which gives rise to compressive stresses at surface (Fig. 4). This promotes growth in the resistance to tigue fracture. Tests show that when the quenching temp ture is increased, the compressive stresses grow and atta level that causes spontaneous detachment of the harde layer at $1200^{\circ} \mathrm{C}$.

The effect of quenching regimes on the endurance of was studied on actual punches of cold-upset automatic chines for making complex-shape bolt heads (Fig. 5). merical studies of the stress state of the punches have sh that high contact stresses exceeding $2500 \mathrm{MPa}$ arise in ation on a small area of the cutting edges at the place of junction (Fig. 6).

Earlier experiments on hardening of working surfai punches by carburizing have shown that inconsidi changes in the process of thermochemical and heat trea affect considerably the endurance of the tools [6]. This plainable by summation of the operating stresses and

TABLE 1. Structure and Properties of Surface Layers of Stecl R6M5

\begin{tabular}{|c|c|c|c|c|c|c|}
\hline \multirow{2}{*}{ Method of treatment } & \multirow{2}{*}{$\begin{array}{l}\text { Numbet } \\
\text { of batch }\end{array}$} & \multirow{2}{*}{$\begin{array}{c}\text { Temperature } \\
\text { of austenization, } \\
{ }^{\circ} \mathrm{C}\end{array}$} & \multirow{2}{*}{$\begin{array}{c}\text { Grain } \\
\text { size No. }\end{array}$} & \multirow{2}{*}{$\begin{array}{l}\text { Thickness } \\
\text { of hardened } \\
\text { layer, mm }\end{array}$} & \multicolumn{2}{|c|}{ Hardness, $H R C_{\mathrm{e}}$} \\
\hline & & & & & of the surface & of the core \\
\hline Volume quenching & 1 & $840-850$ & 10 & .- & $62-63$ & $62-63$ \\
\hline \multirow{3}{*}{$\begin{array}{l}\text { Carburizing and volume } \\
\text { quenching }\end{array}$} & 2 & 950 & 10 & $0.4-0.6$ & $65-66$ & $62-63$ \\
\hline & 3 & 950 & 11 & $0.4-0.6$ & $65-66$ & $60-6 i$ \\
\hline & 4 & 950 & 12 & $0.4-0.6$ & $65-66$ & $55-57$ \\
\hline
\end{tabular}




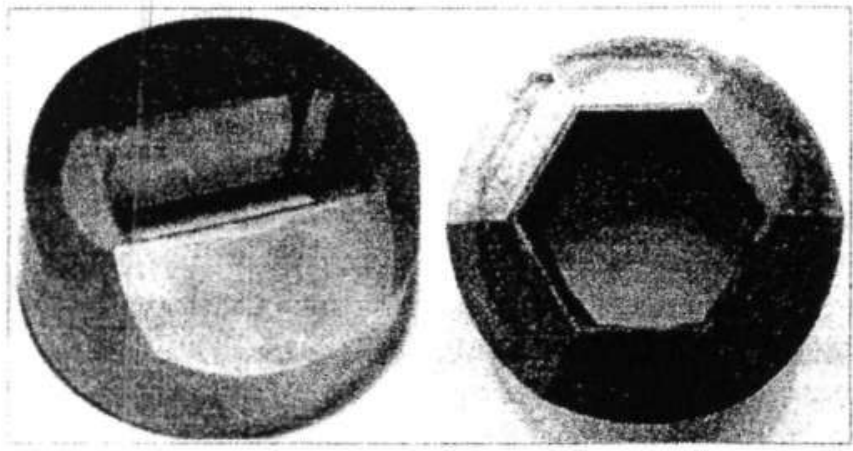

Fig. 5. Punches of cold-upsetting automatic machines.

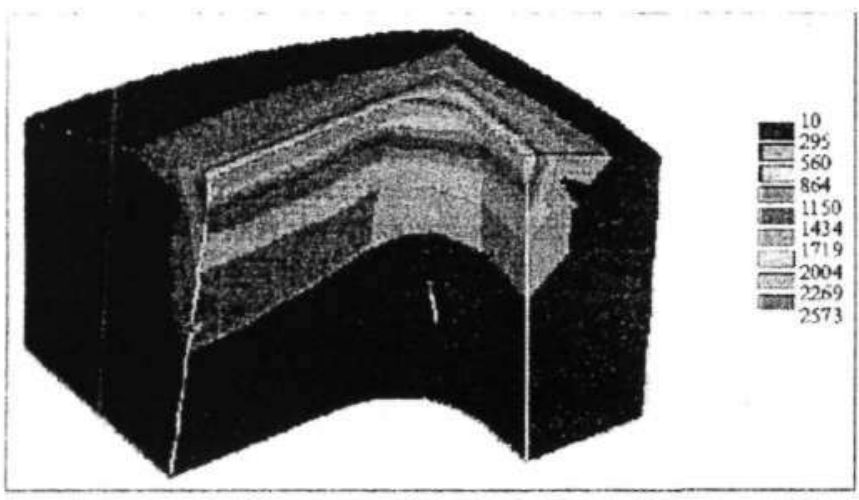

Fig. 6. Distribution of equivalent stresses on the cutting edge of a punch with tetrahedral working cavity (a fourth part of the punch is presented). The rectangles on the right give the stresses in MPa.

residual compressive stresses formed in the carburized layer. It can be seen from Fig. 7 that the value of the resulting stresses depends on the mode of formation of the surface layer. After quenching from $1150^{\circ} \mathrm{C}$ the total value of contact stresses in the hardened layer is the highest and attains $3240 \mathrm{MPa}$. Impact loading of the working surfaces of a punch affects negatively the operating capacity of the surface layer causing its detachment (batch 2 in Fig. 7). Brittle fracture of cutting edges has also been observed in punches having no carburized working surfaces and quenched by the standard method (batch 1 in Fig. 7). After quenching from 950" $\mathrm{C}$ the core has a reduced hardness (55 - $57 \mathrm{HRC}$ ) and is deformed under the operating load, which is accompanied by cracking of the surface layer (batch 4 in Fig. 7). The punches with grain size No. 11 quenched from $1050^{\circ} \mathrm{C}$ exhibit the highest endurance. Their service life before failure increases by $30 \%$ as compared to the punches of the other batches. The working surface of these punches is worn uniformly and without manifested cleavage (batch 3 in Fig. 7); the hardness of their core is high enough $(60-61 H R C)$ and prevents the hardened layer from early cracking.

The data obtained show that the depth gradient of the properties of articles from high-speed steel R6M8 with carburized working surfaces can be controlled by varying the quenching temperature. Knowing the stress-strain pattern in the process of operation of a specific die we can choose the

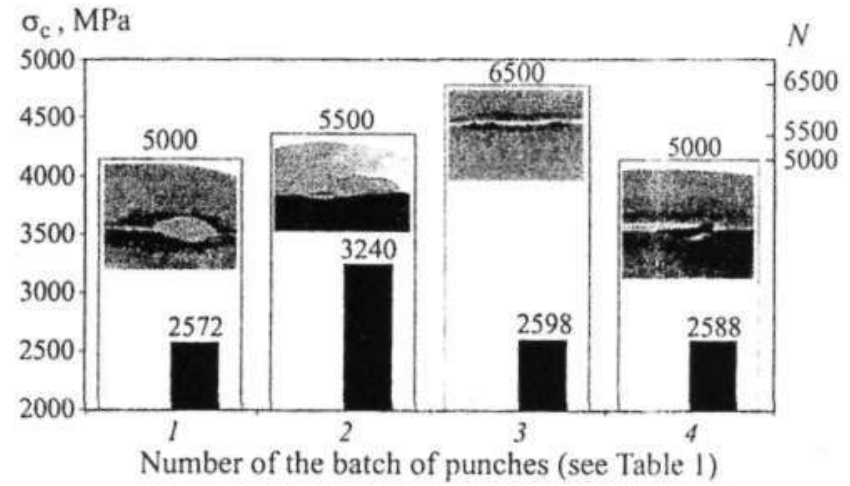

Fig. 7. Effect of the process of heat and thermochemical treatment on the stress state $\left(\sigma_{\mathrm{c}}\right)(\mathbf{m})$, the endurance $(N$ is the number of forgings before failure) ( $\square$ ) and the kind of fracture of the cutting edges of punches.

optimum mode for its heat treatment to provide a maximum endurance.

\section{CONCLUSIONS}

1. It is expedient to subject the functional surfaces of cold-upset punches produced from high-speed steel R6M5 to diffusion carburizing to $1.6-1.8 \%$, quenching from the temperature of $1050^{\circ} \mathrm{C}$ for formation of austenile grains with size No. 12 - 11, and then to triple tempering at $560^{\circ} \mathrm{C}$.

2. By varying the temperature of quenching of tools from high-speed steel R6M5 we can control the residual compressive stresses in the surface layer and the gradient of mechanical properties over the depth of the tools in accordance with their stress-strain state in operation.

3. The process suggested has been tested for cold-upset punches of an automated line of the Gomel Plant for Casting and Normals in the production of bolts for rail fastening and has shown a $25-30 \%$ growth in their endurance.

\section{REFERENCES}

1. Yu. A. Geller, Tool Steels, A Handbook [in Russian], Metallurgiya, Moscow (1975), $584 \mathrm{p}$.

2. I. Artinger, Tool Steels and Their Heat Treatment, A Handbook [Russian translation), Metallurgiya, Moscow (1982).

3. M. M. Severin, Cloud Burst Hardening [in Russian], Mashgiz, Moscow (1955), $312 \mathrm{p}$.

4. A. N. Tarasov, "Structure and properties of diffusion layers formed on alloyed steels due to carburizing in activated charcoal mixtures," Metalloved. Term. Obrab. Met, No. 2, 32 - 35 (2007).

5. E. 1. Bel'skii, M. V. Sitkevich, E. I. Ponkratin, and V. A. Stefanovich, Thermochemical Treatment of Tool Steels [in Russian], Nauka i Tekhnika, Minsk (1986), 248 p.

6. V. M. Ken'ko, V. A. Pigenko, and I. N. Stepankin, "About allowance for the production process in design of upset punches," Kuzn.-Shtamp. Proizvod., No. 10, 26 - 30 (2001).

7. A. V. Belyi, V. A. Kukharenko, and A. P. Patelyuk, Surface Engineering of Structural Materials with Concentrated Flows of Nitrogen Ions [in Russian], Belorusskaya Nauka, Minsk (2007), 244 p.

8. L. 1. Mirkin, A Handbook on x-ray Diffraction Analysis of Polycrystals [in Russian], Fizmatgiz, Moscow (1961), 864 p. 